\title{
Ombitasvir/ Paritaprevir/ Ritonavir + Ribavirin Combination Therapy in Hepatitis C Virus Infected Patients with Genotype 4 in Real-life Practice: A Multicentre Experience
}

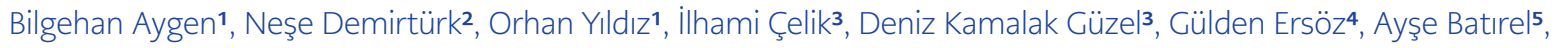

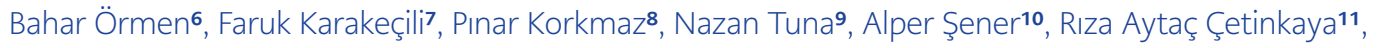

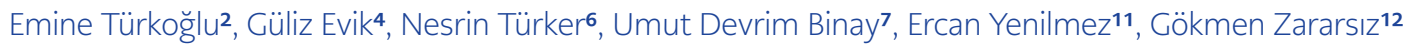

\begin{abstract}
${ }^{1}$ Department of Infectious Diseases and Clinical Microbiology, Erciyes University School of Medicine, Kayseri, Turkey; ${ }^{2}$ Department of Infectious Diseases and Clinical Microbiology, Afyon Kocatepe University School of Medicine, Afyonkarahisar, Turkey; ${ }^{3}$ Department of Infectious Diseases and Clinical Microbiology, University Of Health Sciences, Kayseri Training and Research Hospital, Kayseri, Turkey; ${ }^{4}$ Department of Infectious Diseases and Clinical Microbiology, Mersin University School of Medicine, Mersin, Turkey; ${ }^{\mathbf{5}}$ Department of Infectious Diseases and Clinical Microbiology, University Of Health Sciences, Kartal Dr. Lütfü Kırdar Training and Research Hospital, İstanbul, Turkey; 6 Department of Infectious Diseases and Clinical Microbiology, Katip Çelebi University Atatürk Training and Research Hospital, İmir, Turkey; ${ }^{7}$ Department of Infectious Diseases and Clinical Microbiology, Erzincan University School of Medicine, Erzincan, Turkey; ${ }^{8}$ Department of Infectious Diseases and Clinical Microbiology, Dumlupınar University School of Medicine, Kütahya, Turkey; ${ }^{9}$ Department of Infectious Diseases and Clinical Microbiology, Sakarya Training and Research Hospital, Adapazarı, Turkey; 10 Department of Infectious Diseases and Clinical Microbiology, Onsekiz Mart University School of Medicine, Çanakkale, Turkey; ${ }^{11}$ Department of Infectious Diseases and Clinical Microbiology, University Of Health Sciences, Sultan Abdülhamid Han Training and
\end{abstract} \\ Research Hospital, İstanbul, Turkey; ${ }^{12}$ Department of Biostatistics, Erciyes University School of Medicine, Kayseri, Turkey
}

\begin{abstract}
Objective: Objective: Ombitasvir/paritaprevir/ritonavir (OMV/PTV/r) + ribavirin (RBV) combination improved the efficacy, safety, and tolerability of the treatment of chronic hepatitis $C$ virus (HCV) genotype 4 infection. We described the effectiveness and safety of OMV/PTV/r + RBV therapy in patients with genotype 4 infection.

Materials and Methods: In this prospective cohort study, HCV genotype 4-infected patients treated with OMV/PTV/r + RBV $(\mathrm{n}=55)$ who were registered in a national database were included. Study patients were treatment-naïve or interferon plus RBV-experienced with or without compensated cirrhosis. Demographic, clinical and virological data were analyzed. Details of clinical and laboratory adverse events (AEs) were recorded. Results: The mean age of the patients was 55.2, and $52.7 \%$ were male. The majority of patients were non-cirrhotic (81.8\%), and 69.1\% were treatment-naïve. The HCV RNA level was below $800.000 \mathrm{IU} / \mathrm{mL}$ in 16 of the cases. Seventy-eight percent of the patients had an underlying disease. SVR12 rate was $98 \%$ in all patients. One patient had virological failure. HCV RNA was undetectable at treatment week 4 in $77.6 \%$, at treatment week 8 in $100 \%$, and at end of treatment in 98\%. The SVR12 rates were $100 \%$ and $88.9 \%$ for those without or with compensated cirrhosis $(p=0.176)$. Rates of AEs and AEsassociated treatment discontinuation were $69.1 \%$ and $3.6 \%$ in the patients, respectively. Conclusion: The OBV/PTV/r + RBV combination was found to have high efficacy and safety profile in the patients with chronic HCV genotype 4 infection.
\end{abstract}

Corresponding Author: Bilgehan Aygen

E-mail:

baygen@erciyes.edu.tr

Received: June 27, 2019

Accepted: August 9, 2019

Published: October 7, 2019

\section{Suggested Citation:}

Aygen B, Demirtürk N, Yıldız O, Çelik I, Güzel DK, Ersöz G et al. Ombitasvir/ Paritaprevir/ Ritonavir + Ribavirin Combination Therapy in Hepatitis C Virus Infected Patients with Genotype 4 in Real-life Practice: A Multicentre Experience. Infect Dis Clin Microbiol 2019; 2: 97 106.

DOI: $10.36519 / \mathrm{idcm} .2019 .19014$ 


\section{INTRODUCTION}

A bout 170-200 million people are known to be infected with the hepatitis $\mathrm{C}$ virus (HCV) worldwide. Chronic hepatitis $\mathrm{C}(\mathrm{CHC})$ infection carries risks of hepatic fibrosis, cirrhosis, portal hypertension, liver failure, and hepatocellular carcinoma (HCC) (1-4). Chronic HCV infection is an important health problem in Turkey (5-10). In Turkey, among HCV infections, genotype $1 \mathrm{~b}$ was reported to be the most common one (90\%), while types 2 , 3 , and 4 exist, with lower prevalence. However, recently, there has been an increase in HCV genotype 4 infections in Turkey (9-13). Two studies from Kayseri reported an unusually high proportion of genotype 4 infections reaching up to $35 \%$ among the patients, who were admitted to the hospitals for treatment of $\mathrm{CHC}(14,15)$. This high proportion was significantly higher than the average prevalence of $1.4 \%$ reported for type $4 \mathrm{HCV}$ infections in Turkey (15). It was shown recently that Kayseri genotype 4 isolates were closely related to subtype $4 \mathrm{~d}$ sequences $(13,16)$.

There are several different treatment approaches for HCV genotype 4 infection. By the combination therapy of pegylated interferon (PegINF) and ribavirin (RBV), the sustained virological response (SVR) rate was $60 \%$ in patients infected with HCV genotype 4 (17). First-generation protease inhibitors in combination with PegINF and RBV achieved low rates of response in the patients infected with HCV genotype 4 , and these regimens were characterised by less favourable safety profiles, which affect

\section{HIGHLIGHTS}

- There is an increase in HCV genotype 4 infection in Turkey. The regimen of OBV/PTV/r $+\mathrm{DSV} \pm \mathrm{RBV}$ was highly efficacious to treat HCV genotype 4 infection, including patients with compensated cirrhosis.

- The patients with chronic HCV genotype 4 infection who were treated with OBV/PTV/r + RBV for 12 weeks achieved 98\% SVR12 in our study. Adverse events were mostly mild and did not require medical intervention This cohort is the first to present real-life data in our country. adherence to the PegINF-based therapy $(7,11,12)$. The novel INF-free second-generation direct-acting antivirals (DAAs) therapy consisting of ombitasvir (OBV)/paritaprevir (PTV)/ritonavir $(\mathrm{r}) \pm$ dasabuvir (DSV) \pm RBV improved the efficacy, safety, and tolerability of the treatment of chronic HCV infection. This combination has also proved effective not only in genotype 1 but also in genotype 4. Patients with genotype 4 infection were recommended to be treated with the combination of OBV/PTV/r + RBV, which also resulted in high SVR rates in clinical and real-world trials (18-22). Three of these medications target HCV at different phases of the viral life cycle. Two of them were protease inhibitors: OBV inhibits viral NS5A phosphoprotein, which was involved in virus assembly and PTV inhibited viral NS3-4A serine protease involved in proteolytic processing. Furthermore, ritonavir enhances the pharmacokinetic properties of PTV, increasing their availability through improved drug exposure (23). We aimed to assess the efficacy and safety of OMV/ $\mathrm{PTV} / \mathrm{r}+\mathrm{RBV}$ combination in genotype 4 infected patients in real clinical practice.

\section{MATERIALS AND METHODS}

\section{Study population}

The patients older than 18 years, with chronic HCV genotype 4 infection, treatment-naïve or previously treated with PegINF/RBV, and chronic hepatitis or compensated cirrhosis were included in the study.

The patients with genotype non-4 HCV infection, decompensated liver cirrhosis with Child-Pugh class B or C, evidence of HCC, a concomitant medication that was contraindicated according to manufacturer's recommendations, current pregnancy, lactation, and platelets count $<25.000 / \mathrm{mm}_{3}$ were excluded.

We enrolled patients for treatment with OBV/PTV/r + RBV according to the therapeutic guidelines of the National Health Application Notice of the Ministry of Health (24). The clinical information about baseline demographic characteristics, prior treatment status, baseline viral load, liver function tests [bilirubin, alanine aminotransferase (ALT), aspartate aminotransferase (AST), albumin], haemoglobin, platelets count, international normalized ratio 
(INR), degree of fibrosis according to liver biopsy, antiviral treatment history, co-infection status, underlying diseases and concomitant medications were recorded.

\section{Study design}

This was a retrospective, non-randomized, multicentre, national study evaluating OBV/PTV/r + RBV treatment of HCV infected patients with genotype 4 in routine clinical practice.

Data were collected through a National Registry under the auspices of the Study Group for Viral Hepatitis of the Turkish Society of Clinical Microbiology and Infectious Diseases. All of the subjects provided the written informed consent for treatment. The study recorded data from all patients chronically infected with HCV genotypes 4 undergoing treatment with OMV/PTV/r + RBV in 11 Turkish centres between April 1, 2017, and August 31, 2018. We included data from 55 patients in the analysis. The follow-up period was 24 weeks. The Ethics Committee for Clinical Research of Kocatepe University approved the study with the number of 2017-4.

We collected effectiveness and safety data at different time points, both during treatment and after treatment completion.

\section{Therapy and follow-up}

The patients received two tablets of OBV/PTV/r (Viekirax 12.5 mg /75 mg /50 mg per tablet; Fournier Laboratories Ireland Limited Anngrove, Carrigtwohill, Co.Cork Ireland) once a day. The RBV dose, when administered, was weight-based $(<75$ kg, 1000 mg/day; >75 kg, 1200 mg/day). The patients were treated with OBV/PTV/r + RBV for 12 weeks. In the case of significant laboratory abnormalities at baseline [anaemia, thrombocytopenia or chronic renal failure (CRF)] treatment was started with a lower dose of RBV, according to product characteristics. The RBV dose was modified or discontinued in the therapy of patients who developed severe adverse events or laboratory abnormalities. If necessary, we modified the medications according to the drug interactions. In renal transplant recipients, the doses of tacrolimus were reduced according to plasma concentrations.
We assessed the clinical signs, adverse events (AEs) and laboratory parameters at the baseline, at the 4 th and 8th weeks, at the end of treatment (EOT, week 12), 12 weeks after EOT (FU12), and at the end of treatment if the premature discontinuation happened.

\section{Efficacy and safety analysis}

The primary endpoint of effectiveness was the achievement of SVR (HCV RNA undetectable or below detection threshold) at FU12. Secondary endpoints were the assessment of virological responses at 4th week (RVR, rapid virological response), at 8th week, and at EOT. Virological failure was defined as virological relapse (undetectable HCV RNA at the end of treatment, but positive within 12 weeks post-treatment), and non-response (HCV RNA was detectable at the end of treatment). Quantitative HCV RNA measurement was performed using various commercial real-time PCR quantification kits. The detection threshold was $12-25 \mathrm{IU} / \mathrm{mL}$ in the study centres.

Safety endpoints included AEs and laboratory abnormalities .

\section{Statistical Analysis}

The analyses were carried out on the per-protocol population, which comprises 55 patients. Histogram, q-q plots and Shapiro-Wilk's test was assessed to test the data normality. A logarithmic transformation (base 10) was applied to HCV-RNA due to its highly skewed distribution. Levene test was used to test variance homogeneity. Mauchly's test was used to test the sphericity. To compare the virological response distribution among non-cirrhotic/cirrhotic and type of treatment; either Pearson chi-square analysis or Fisher exact test was applied. Bonferroni corrected $\mathrm{z}$ test was used for multiple comparisons. To compare the laboratory parameters among follow-up time points, either a repeated-measures analysis of variance (ANOVA) or Friedman test was performed. Analyzes were conducted using TURCOSA (Turcosa Analytics Ltd Co, Turkey, www.turcosa.com.tr) statistical software. The statistical significance was set as less than $5 \%$. 
Table 1. Baseline demographical and clinical characteristics.

\begin{tabular}{|c|c|}
\hline Patient characteristics & $n=55(\%)$ \\
\hline Gender (male) & $29(52.7)$ \\
\hline Age & $55.2 \pm 14.9(23-85)$ \\
\hline Treatment-naïve & $38(69.1)$ \\
\hline Non-cirrhotic & $29(76.3)$ \\
\hline Compensated cirrhotic & $9(23.7)$ \\
\hline Treatment-experienced & $17(30.9)$ \\
\hline Non-cirrhotic & $16(94.1)$ \\
\hline Compensated cirrhotic & $1(5.9)$ \\
\hline HCV RNA, $\log _{10} \mathrm{IU} / \mathrm{mL}$ & $6.1 \pm 0.7(4.5-7.2)$ \\
\hline$\geq 800.000, \mathrm{IU} / \mathrm{L}$ & 39 (70.9) \\
\hline ALT, IU/L & $32(22-56)$ \\
\hline AST, IU/L & $31(21-53)$ \\
\hline Total bilirubin, mg/dL & $0.7(0.6-1)(\mathrm{nmd}=3)$ \\
\hline Albumin, g/dL & $4.1 \pm 0.6(3-5.6)(\mathrm{nmd}=4)$ \\
\hline Haemoglobin, g/dL & $13.9 \pm 2(10.4-17.9)$ \\
\hline Platelets count, $/ 1000 \mathrm{~mm}^{3}$ & $216(165-262)$ \\
\hline INR & $1(0.9-1.2)(n m d=2)$ \\
\hline \multicolumn{2}{|l|}{ Fibrosis stage* } \\
\hline F1 & $7(12.7)$ \\
\hline F2 & $5(9.1)$ \\
\hline F3 & $14(25.5)$ \\
\hline F4 & $1(1.8)$ \\
\hline F5 & $6(10.9)$ \\
\hline F6 & $3(5.5)$ \\
\hline Unknown & $19(34.5)$ \\
\hline \multicolumn{2}{|l|}{ Antiviral treatment history } \\
\hline \multicolumn{2}{|l|}{ Number of experience } \\
\hline 1 & $16(94.1)$ \\
\hline$>1$ & $1(5.9)$ \\
\hline \multicolumn{2}{|l|}{ Treatment regimens } \\
\hline PegINF + RBV & $16(94.1)$ \\
\hline PegINF + RBV/ Peg INF + RBV & $1(5.9)$ \\
\hline
\end{tabular}




\section{Continue to Table 1}

\begin{tabular}{|c|c|}
\hline Patient characteristics & $\mathrm{n}=55(\%)$ \\
\hline \multicolumn{2}{|l|}{ Treatment responses } \\
\hline Non-responders & $8(47.1)$ \\
\hline Relapsers & $6(35.3)$ \\
\hline Discontinued due to AEs & $1(5.9)$ \\
\hline Breaktrough & $1(5.9)$ \\
\hline Unknown & $1(5.9)$ \\
\hline HBV co-infection & $1(1.8)$ \\
\hline HIV co- infection & $2(3.6)$ \\
\hline Associated diseases & $43(78.2)$ \\
\hline \multicolumn{2}{|l|}{ Number of diseases } \\
\hline 1 & $28(65.1)$ \\
\hline$>1$ & $15(34.9)$ \\
\hline \multicolumn{2}{|l|}{ Definition of disease } \\
\hline Diabetes mellitus & $12(21.8)$ \\
\hline Cardiovascular ${ }^{a}$ & $11(20.0)$ \\
\hline Chronic renal failure & $11(20.0)$ \\
\hline Hematologic diseases ${ }^{b}$ & $4(7.3)$ \\
\hline Kidney transplantations & $2(3.6)$ \\
\hline Lung diseases ${ }^{c}$ & $1(1.8)$ \\
\hline Neurological diseases $^{d}$ & $1(1.8)$ \\
\hline Psychiatric diseases ${ }^{e}$ & $1(1.8)$ \\
\hline Thyroid diseases ${ }^{f}$ & $1(1.8)$ \\
\hline Dermatological diseasesg & $1(1.8)$ \\
\hline Otherh & $3(5.5)$ \\
\hline Modification of concomitant medications & $16(29.1)$ \\
\hline
\end{tabular}

All data are presented as mean \pm standart deviation (range) or median( $1^{\text {st }}-3^{\text {rd }}$ quartiles), unless indicated otherwise.

nmd: number of missing data; HCV: hepatitis C virus; ALT: alanin aminotransferase; AST: aspartate aminotransferase; INR: international normalized ratio; PegINF: pegylated interferon; INF: interferon; RBV: ribavirin; AEs: adverse events;

HBV: hepatitis B virus; HIV: human immunodeficiency virus; HDV: hepatitis D virus.
* Ishak scoring system.

a Hypertension, arrhythmia, valvular disease, aortic aneurism, heart failure, hyperlipidemia, peripheral vascular diseases;

b Thalassemia, hemophilia, lymphoma, multiple myeloma;

'Asthma;

dAlzeimer;

e Depression;

fHypothyroidism;

g Vitiligo;

${ }^{\text {h }}$ Familial mediterranean fever, reflux, hydatid cyst. 


\section{RESULTS}

The demographic and clinical baseline characteristics were shown in Table 1. The mean age of the patients was 55.2 years, and $52.7 \%$ were male. The majority of the patients were non-cirrhotic, (81.8\%) and $69.1 \%$ were treatment-naïve. The HCV RNA level was below 800,000 IU/mL in 16 cases. Liver biopsy was performed in 36 patients (65.5\%). The fibrosis score was 1 or 3 in the majority of the patients. Compared to prior treatment responses, $47.1 \%$ of the patients did not respond, and 35.3\% relapsed. Two patients had HIV, and one had HBV co-infection. The HBV DNA was negative in HBsAg positive patient before HCV treatment. $78 \%$ of the patients had an underlying disease. The most common comorbidities were diabetes mellitus (22\%), cardiovascular diseases (20\%) and CRF (20\%). In $29.1 \%$ of the patients, concomitant medications were modified because of drug interactions. At the baseline, the mean values of ALT was $32 \mathrm{IU} / \mathrm{L}$, AST $31 \mathrm{IU} / \mathrm{L}$, bilirubin $0.73 \mathrm{mg} / \mathrm{dL}$, albumin $4.14 \mathrm{~g} / \mathrm{dL}$, haemoglobin $13.91 \mathrm{mg} / \mathrm{dL}$, platelet count $216 / 1000 \mathrm{~mm}_{3}$ and INR was 1.

\section{Efficacy and safety outcomes}

Out of the 55 analysed patients, 1 patient did not return for viral load follow up (FU) at 12th week, two patients stopped antiviral therapy because of AEs, and one patient died. Virological rates by the per-protocol analysis were calculated. FU12 data were available for 51 patients, among whom 50 (98\%) achieved SVR12. HCV RNA was undetectable at treatment week 4 in $77.6 \%$, at treatment week 8 in $100 \%$, and at the end of treatment in $98 \%$.

The rates of SVR according to the presence or absence of cirrhosis in treatment-naive or -experienced patients were shown in Figure 1. The SVR12 rates were $100 \%$ and $88.9 \%$ for those with or without compensated cirrhosis. $(\mathrm{p}=0.176)$. The SVR12 ratio in treatment-naïve and non-cirrhotic patients was higher than in compensated cirrhotic patients with no statistical significance $(p=0.235)$. SVR12 rate in treatment-experienced patients was higher than in treatment-naïve patients, but the difference was not statistically significant $(\mathrm{p}=0.177)$. SVR12 was achieved in 10 of 11 patients (90.9\%) with CRF. One patient died in this group. SVR12 was obtained in two patients (100\%) with HIV co-infection and two patients $(100 \%)$ with kidney transplant patients.

The differences between baseline and different time points during antiviral therapy were presented in Table 2. The mean ALT level significantly decreased from $32 \mathrm{IU} / \mathrm{L}$ at baseline to $16 \mathrm{IU} / \mathrm{L}$ after the four week of the treatment and to $15 \mathrm{IU} / \mathrm{L}$ at the EOT ( $<<0.001)$. The AST and haemoglobin values decreased from baseline to FU12 ( $<<0.001$ and $p<0.001)$. The platelet count increased in FU12 compared to baseline level $(p=0.081)$.

Five patients (9.1\%) failed to achieve SVR12. One patient did not respond to the therapy, One patient with CRF died at the 6th week of treatment, because of gastric bleeding unrelated to liver disease, two pa-

Table 2. Median laboratory parameters changes between baseline and 12 weeks post-treatment.

\begin{tabular}{|c|c|c|c|c|c|c|}
\hline \multirow{2}{*}{$\begin{array}{l}\text { Patients }(n=51 \text { ) } \\
\text { (number of complete cases }=48 \text { ) }\end{array}$} & \multicolumn{5}{|c|}{ Follow-up time points } & \multirow{2}{*}{$p$ value } \\
\hline & Baseline & Week 4 & Week 8 & ЕОT (Week 12) & FU12 & \\
\hline$A L T, I U / L$ & $32(22.3-55.5)^{\mathrm{a}}$ & $16(12-27.5)^{b}$ & $14.5(11.3-19.8)^{b}$ & $15(12-19.8)^{b}$ & $17(12-23)^{b}$ & $<0.001$ \\
\hline AST, IU/L & $31(21.3-53)^{\mathrm{a}}$ & $18(14-22)^{b}$ & $16(12-21.8)^{b}$ & $16(12-19)^{b}$ & $18.5(14-22.8)^{b}$ & $<0.001$ \\
\hline Haemoglobin, g/dL & $14.1 \pm 2^{\mathrm{a}}$ & $13.2 \pm 2.3^{b}$ & $13 \pm 2.1^{b}$ & $12.9 \pm 2.08^{b}$ & $13.3 \pm 2.2^{b}$ & $<0.001$ \\
\hline Platelet count, /1000 mm & $217(167.5-269.5)$ & $242(192.3-295.8)$ & $220.5(187-282.5)$ & $231.5(186.3-284.5)$ & $237(186-278)$ & 0.081 \\
\hline
\end{tabular}

All data are presented as mean \pm standart deviation (range) or median( $1^{\text {st }}-3^{\text {rd }}$ quartiles), unless indicated otherwise. ALT: alanin aminotransferase; AST: aspartate aminotransferase; EOT: End of treatment; FU12: follow-up 12 week after EOT. Different superscripts in the same row indicates a statistically significant difference among time points. 
tients discontinued because of AEs and one patient was lost in FU. The patient with virological failure was treatment-naïve and had cirrhosis.

Adverse events and laboratory abnormalities were shown in Table 3. There was at least one AE among 38 patients (69.1\%). One CRF patient died after she achieved RVR due to gastric bleeding. In our cohort, two patients $(3.6 \%)$ stopped the therapy within 3 weeks after the start of treatment because of AEs or laboratory abnormalities: one patient had jaundice and hepatotoxicity (total bilirubin $5.6 \mathrm{mg} / \mathrm{dL}$, ALT 363 IU/L, AST 352 IU/L and total bilirubin 11.7 mg/dL, ALT 476 IU/L, AST 389 IU/L, respectively) and therapy was stopped after 14 days; another patient had jaundice (total bilirubin: $10.8 \mathrm{mg} / \mathrm{dL}$ and total bilirubin: $9.1 \mathrm{mg} / \mathrm{dL}$, respectively) and therapy was stopped after 21 days.

The most common AEs were asthenia (9.1\%), fatigue $(5.5 \%)$, and mild rash (5.5\%) (Table 3 ). AEs were mostly mild and did not require medical intervention. Because of anaemia, RBV dose was reduction in four (7.3\%) patients, and RBV was discontinued in one (1.8\%) patient. Erythrocyte transfusion was performed in two (3.6\%) patients. HBV reactivation was not observed.

\section{DISCUSSION}

Patients with HCV infection are at risk for progression to cirrhosis, transplantation, liver-related and all-cause mortality. The use of DAAs has considerably improved therapeutic outcomes for patients with chronic HCV infections. High SVR12 was achieved in treatment-naïve or -experienced patients with chronic HCV genotype 1/4 infections, including patients without cirrhosis or with cirrhosis who received OBV/PTV/r + RBV (18-20). Real-world evidence can provide insights into the effectiveness and safety of therapeutic regimens in broader patient populations and a more diverse clinical setting (25).

We analysed the real-world effectiveness of OBV/ $\mathrm{PTV} / \mathrm{r}+\mathrm{RBV}$ in 55 patients with HCV genotype 4 infection treated in 11 health care centres in Turkey. The SVR12 rate was $98 \%$ in all patients. The study population included a considerable number of
Table 3. Adverse events and laboratory abnormalities.

\begin{tabular}{|c|c|}
\hline Patients & $n=55(\%)$ \\
\hline Any AEs & 38 (69.1) \\
\hline $\begin{array}{l}\text { AEs or laboratory abnormalities leading to } \\
\text { treatment discontinuation }\end{array}$ & $2(3.6)$ \\
\hline \multicolumn{2}{|l|}{ Adverse events } \\
\hline Asthenia & $5(9.1)$ \\
\hline Fatigue & $3(5.5)$ \\
\hline Mild rash & $3(5.5)$ \\
\hline Anorexia & $2(3.6)$ \\
\hline Diarrhea & $2(3.6)$ \\
\hline Pruritus & $2(3.6)$ \\
\hline Headache & $1(1.8)$ \\
\hline Nausea & $1(1.8)$ \\
\hline Cough & $1(1.8)$ \\
\hline Dry skin & $1(1.8)$ \\
\hline Vomiting & $1(1.8)$ \\
\hline \multicolumn{2}{|l|}{ Haemoglobin } \\
\hline$<10-8 \mathrm{~g} / \mathrm{dL}$ & $7(12.7)$ \\
\hline$<8-6.5 \mathrm{~g} / \mathrm{dL}$ & $1(1.8)$ \\
\hline \multicolumn{2}{|l|}{ Total bilirubin } \\
\hline$>1.5-3 \times$ ULN & $4(7.3)$ \\
\hline$>3-10 \times$ ULN & $2(3.6)^{\alpha \beta}$ \\
\hline \multicolumn{2}{|l|}{ ALT } \\
\hline$>3-5 \times$ ULN & - \\
\hline$>5-20 \times$ ULN & $1(1.8)^{\alpha}$ \\
\hline \multicolumn{2}{|l|}{ AST } \\
\hline$>3-5 \times$ ULN & - \\
\hline$>5-20 \times$ ULN & $1(1.8)^{\alpha}$ \\
\hline
\end{tabular}

AEs: adverse events; ALT: alanin aminotransferase;

AST: aspartate aminotransferase;

ULN: upper limit of normal.

${ }^{a}$ Treatment was discontinued;

${ }^{\boldsymbol{\beta}}$ Transaminases were high in one patient. 
treatment-naïve (69.1\%) and non-cirrhotic patients (81.8\%). SVR12 ratios were $97.1 \%$ in treatment-naïve patients, $100 \%$ in treatment-experienced patients, $100 \%$ in non-cirrhotic patients and $88.9 \%$ in cirrhotic patients. SVR12 ratio was higher in non-cirrhotic patients compared to compensated cirrhotic patients. There was no significant difference in the ratio of SVR12 between treatment-naïve and -experienced patients. Analysis of clinical trials and real-world experiences of OBV/PTV/r \pm RBV based regimens demonstrated overall $91-100 \%$ SVR rates in patients with HCV genotype 4 infection (18-20, $22,24,25)$. Thus, the current study results were similar to high SVR12 rates noted in real-world studies.

In our study, virological response rates were $77.6 \%$ in the 4 th week of treatment, $100 \%$ in the 8 th week of treatment and $98 \%$ in the EOT. In a Spanish study of $72.9 \%$ of cirrhotic patients, the RVR rate was $77.6 \%$, and the EOT ratio was $97.3 \%$ (23).

One patient had virological failure in our study. Resistance testing is not routinely performed in Turkey. Our results confirm the similarly low rates of virological failure in individuals treated with OBV/ $\mathrm{PTV} / \mathrm{r}+\mathrm{RBV}$ previously observed in clinical trial and real-world data $(23,25)$.

In our cohort, results demonstrate high SVR12 rates with OBV/PTV/r + RBV in all the patients irrespective of cirrhosis status or previous treatment history. In Turkey, HCV patients are managed by experienced clinicians in referral centres because of the national program for HCV treatment, which may result in better treatment adherence and higher response rates. A meta-analysis of 20 unique patient cohorts across 25 studies encompassing 5158 patients reported the overall SVR12 rates of 98.9\% (95\% confidence interval (CI): 94.2 - 100) in genotype 4 infected patients (25). SVR12 rates were consistently high irrespective of cirrhosis status or prior HCV treatment experience.

$\mathrm{OBV} / \mathrm{PTV} / \mathrm{r} \pm \mathrm{RBV}$ combination has demonstrated a very good safety profile in clinical trials (18-20). Rates of serious AEs and serious AE-associated discontinuation were $5.7 \%$ and $2.5 \%$, respectively, in the study of Crespo J et al. (22). In our study, $69.1 \%$ of the patients reported at least one $\mathrm{AE}$ and most
Figure 1. Rates of virological response to ombitasvir/paritaprevir/ ritonavir + ribavirin.

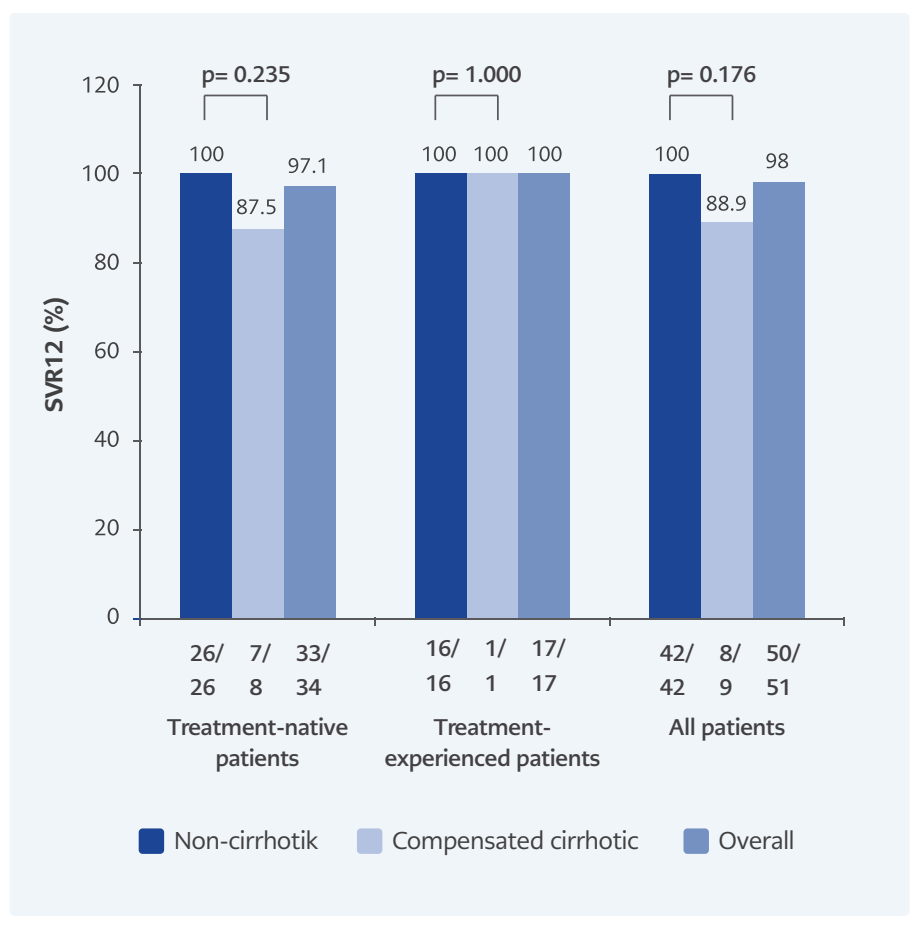

SVR12: sustained virological response at week 12 psot-treatment

of the AEs were mild or moderate. The frequency of treatment discontinuation due to AEs was 3.6\%.

Drug interaction is another important issue for $\mathrm{OBV} / \mathrm{PTV} / \mathrm{r} \pm \mathrm{DSV} \pm \mathrm{RBV}$ therapy. The routine medication was modified at baseline because of potential drug interactions in 16 (13.1\%) patients in our cohort. In the study of González-Colominas E et al. (26), at least one potential drug interaction was reported in $62.1 \%$ of the patients and concomitant medication was modified before HCV treatment in $27.7 \%$ of the patients. Necessary modifications were made in concomitant medications on account of drug interactions, and the high success rate was obtained in patients with underlying disease such as kidney transplantation and HIV co-infection (27, 28).

Efficacy of OMV/PTV/r + RBV was very high in our cohort of patients with underlying diseases. OMV/ $\mathrm{PTV} / \mathrm{r}$ combination does not require dose modification for those with end-stage renal disease, with or without dialysis. This combination was found to be 
highly effective and safe in patients with $\operatorname{CRF}(25,28$, 29). The real-world SVR rate for patients with stage 4 or 5 CRF, including those on dialysis have been reported to be $97 \%$ (25). In our study, the SVR12 rate was found to be $90.9 \%$ in patients with CRF.

In Turkey, DAA regimens are not easily accessible because of their high costs and the national legal restrictions for patients who will receive HCV treatment free of charge. The present study has some limitations. First, the number of patients compensated cirrhotic were relatively low when compared with many real-world cohorts. Second, the study was uncontrolled, retrospective, and there was no external monitoring of the collected data. Third, the quantification of HCV viral load and genotyping were conducted at several laboratories. Nevertheless, this study is of great value, as it is the report to reflect effectiveness and safety outcomes in real-life clinical practice in our country. Efficacy of $\mathrm{OMV} / \mathrm{PTV} / \mathrm{r}+\mathrm{RBV}$ was very high in our cohort of patients with non-cirrhosis or compensated cirrhosis and with underlying diseases such as chronic renal failure, HIV, and transplantation.

In summary, The OBV/PTV/r + RBV combination was demonstrated high efficacy and safety profile in our cohort. The patients with chronic HCV genotype 4 infection and with or without compensated cirrhosis who were treated with OBV/PTV/r + RBV for 12 weeks achieved 98\% SVR12.PTV/r + RBV for 12 weeks achieved $98 \%$ SVR12.
Ethics Committee Approval: The Ethics Committee for Clinical Research of Kocatepe University approved the study with the number of 2017-4.

Informed Consent: Written informed consent was obtained from the patients who participated in this study.

Peer-review: Externally peer-reviewed.

Author Contributions: Concept - B.A, N.D.; Design - B.A; Supervision - B.A, N.D.; Materials - B.A, N.D.; Data Collection and/ or Processing - B.A., N.D., O.Y., İ.Ç., D.K.G., G.E., A.E., B.Ö., F.K., P.K., N.T., A.Ş., R.A.Ç., E.T., G.E., N.T., U.D.B., E.Y.; Analysis and/or Interpretation - B.A, G.Z.; Literature Review - B.A.; Writer B.A.; Critical Review - B.A.; Other - N.D.

Conflict of Interest: The authors have no conflict of interest to declare.

Financial Disclosure: The authors declared that this study has received no financial support.

\section{REFERENCES}

1 Zare F, Fattahi MR, Sepehrimanesh M, Safarpour AR. Economic burden of hepatitis $C$ virus infection in different stages of disease: A report from Southern Iran. Hepat Mon 2016;16: e32654.

2 Lavanchy D. The global burden of hepatitis C. Liver Int 2009; 29: 74-81.

3 World Health Organization. Hepatitis C Fact Sheet. Updated 2018 July 18 (cited 2018 December 3). Available from: URL: https://www.who.int/en/news-room/fact-sheets/detail/hepatitis-c.

4 van der Meer AJ, Veldt BJ, Feld JJ, Wedemeyer H, Dufour JF, Lammert F, et al. Association between sustained virological response and all-cause mortality among patients with chronic hepatitis C and advanced hepatic fibrosis. JAMA 2012; 308: 2584-93.

5 Aygen B. Hepatitis C. Turkiye Klinikleri J Int Med Sci 2006; 2 : 21-33.
6 Bozkurt I, Aygen B, Gökahmetoglu S, Yildiz O. Hepatitis C and occult hepatitis $C$ infection among hemodialysis patients from Central Anatolia. J Pure Appl Microbiol 2014: 8: 435-40.

7 Aygen B, Ylldız O, Akhan S, Çelen MK, Ural O, Koruk ST, et al. Retreatment of chronic hepatitis $C$ infection with telaprevir: Preliminary results in Turkey. Balkan Med J 2015; 32: 266-72.

8 Aygen B, Nemirtürk N, Türker N, et al. Management of chronic hepatitis C virus infection: A consensus report of the Study Group for Viral Hepatitis of the Turkish Society of Clinical Microbiology and Infectious Diseases-2017 Update. Klimik Journal 2017; 30: 2-36.

9 Aygen B, Yildiz O, Akhan S, Gunal O, Taheri S, Zararsiz G, et al. Impact of interleukin 28B genotype on the virological responses in chronic hepatitis C treatment. Gastroenterology Res 2014; 7: 123-30

10 Taheri S, Aygen B, Korkmaz K, Yildiz O, Zararsiz G, Canatan H. 
Characterization of the interleukin-28B gene rs12979860 C/T polymorphism in Turkish chronic hepatitis C patients and healthy individuals. Balkan Med J 2015; 32: 147-55.

11 Aygen B, Ylldız O, Gökahmetoğlu S, Taheri S, Türe Z. Telaprevir combination therapy in patients infected with hepatitis C virus genotype 4. J Immunol Clin Microbiol 2016; 1:57-61.

12 Aygen B, Yıldız O, Gökahmetoğlu S, Taheri S, Baltac S. Sofosbuvir plus ledipasvir treatment in patients with hepatitis $C$ gen otype $4 \mathrm{~d}$ infection who previously failed to achieve sustained virological response with telaprevir or boceprevir combination therapies. Austin Pharmacol Pharm 2018; 3: 1012.

13 Ciccozzi M, Zehender G, Polat C, Lai A, Kayman T, Sorrentino C et al. Phylogenetic analysis of HCV-4d in Turkey: The curious case of Kayseri province. J Med Virol 2014; 86: 454-60.

14 Gökahmetoğlu S, Atalay MA, Kllnnç A. Determination of the hepatitis $C$ virus genotypes with "pyrosequencing" method. Erciyes Medical Journal 2011; 33: 99-102.

15 Kayman T, Polat C, Ergör G, Abacioğlu YH. Characterization of HCV genotype 4d infections in Kayseri, Turkey. Turk J Med Sci 2015; 45: 547-52.

16 Gökahmetoglu S, Polat C, Atalay MA, et al. Molecular epidemiology of hepatitis $C$ virus genotype 4 isolates in Kayseri. In: Abstracts of 32nd Clinical Virology Symposium (Daytona Beach, Florida, May 19-22, 2016). Washington; DC: American Society for Microbiology, 2016; 82.

17 Kamal SM, Nasser IA. Hepatitis C genotype 4: what we know and what we don't yet know. Hepatology 2008; 47: 1371-83.

18 Hezode C, Asselah T, Reddy KR, Hassanein T, Berenguer M, Fleischer-Stepniewska $\mathrm{K}$, et al. Ombitasvir plus paritaprevir plus ritonavir with or without ribavirin in treatment-naïve and treatment-experienced patients with genotype 4 chronic hepatitis $C$ virus infection (PEARL-I): A randomised, open-label trial. Lancet 2015; 385: 2502-9.

19 Asselah T, Hézode C, Qaqish RB, EIKHashab M, Hassanein T, Papatheodoridis, et al. Ombitasvir, paritaprevir, and ritonavir plus ribavirin in adults with hepatitis $C$ virus genotype 4 infection and cirrhosis (AGATE-I): A multicentre, phase 3, randomised open-label trial. Lancet Gastroenterol Hepatol 2016; 1: 25-35.

20 Waked I, Shiha G, Qaqish RB, Esmat G, Yosry A, Hassany M, et al. Ombitasvir, paritaprevir, and ritonavir plus ribavirin for chronic hepatitis $C$ virus genotype 4 infection in Egyptian patients with or without compensated cirrhosis (AGATE-II): A multicentre, phase 3, partly randomised open-label trial. Lancet Gastroenterol Hepatol 2016; 1: 36-44.
21 Keating GM. Ombitasvir/paritaprevir/ritonavir: A review in chronic HCV genotype 4 infection. Drugs 2016; 76: 1203-11.

22 Crespo J, Calleja JL, Fernández I, Sacristan B, Ruiz-Antorán B, Ampuera J, et al. Real-world effectiveness and safety of oral combination antiviral therapy for hepatitis $C$ virus genotype 4 infection. Clin Gastroenterol Hepatol 2017; 15: 945-9.

23 Perelló C, Carrión JA, Ruiz-Antorán B, et al. Effectiveness and safety of ombitasvir, paritaprevir, ritonavir \pm dasabuvir \pm ribavirin: an early access programme for Spanish patients with genotype $1 / 4$ chronic hepatitis $C$ virus infection. J Viral Hepat 2017; 24: 226-37.

24 Sosyal Güvenlik Kurumu Sağlık Uygulama Tebliği, 4.2.13. Hepatit Tedavisi (cited 2019 June 04). Available from: URL: http:// www.sgk.gov.tr/wps/portal/sgk/tr/kurumsal/merkez-teskilati/ana hizmet birimleri/gss genel mudurlugu/anasayfa duyurular/guncel sut 28122018.

25 Wedemeyer H, Craxi A, Zuckerman E, Dieterich D, Fliak R, Roberts SK, et al. Real-world effectiveness of ombitasvir/paritaprevir/ritonavir+/- dasabuvir+/-ribavirin in patients with hepatitis $C$ virus genotype 1 or 4 infection: A meta-analysis. J Viral Hepat 2017;24(11):936-43.

26 González-Colominas E, Londoño MC, Morillas RM, Torras X, Mojal S, Lens S, et al. Potential drug-drug interactions of ombitasvir, paritaprevir/ritonavir \pm dasabuvir \pm ribavirin in clinical practice. J Gastroenterol Hepatol 2018; 33: 1100-7.

27 Sessa M, Bernardi FF, Vitale A, Schiavone B, Gritti G, Mascolo A, et al. Adverse drug reactions during hepatitis $C$ treatment with direct-acting antivirals: The role of medication errors, their impact on treatment discontinuation and their preventability. New insights from the Campania Region (Italy) spontaneous reporting system. J Clin Pharm Ther 2018;43(6):867-76.

28 Muñoz-Gómez R, Rincón D, Ahumada A, Hernández E, Devesa MJ, Izquierdo S, et al. Therapy with ombitasvir/paritaprevir/ritonavir plus dasabuvir is effective and safe for the treatment of genotypes 1 and 4 hepatitis C virus (HCV) infection in patients with severe renal impairment: A multicentre experience. J Viral Hepat 2017; 24: 464-71.

29 Abad S, Vega A, Hernández E, Mérida E, d Sequera P, Albalate M, et al. Universal sustained viral response to the combination of ombitasvir/paritaprevir/ritonavir and dasabuvir with/without ribavirin in patients on hemodialysis infected with hepatitis $C$ virus genotypes 1 and 4. Am J Nephrol 2017; 45: 267-72. 